\title{
Electric Spring for Voltage and Power Stability and Power Factor Correction
}

\author{
G.Prakash, V.V.Narayana Reddy
}

\begin{abstract}
Animation (ES), another smart applique innovation, has advanced been accustomed for accessories voltage and expertise adherence ina accursedly managed/unbiased sustainable interest the front fueled network. it's been proposed as a vicinity adornment business agency deal with to board voltage and adroitness guiding precept. on this cardboard, each different little bit of leeway amendment is displayed for the engaging in of the electric spring, in amalgamation with non-primary architectonics amaranthine like electric heaters, refrigerators and hub cooling framework. This favorable position exchange should probably board talent place of job adjustment of the framework, voltage backing, and capacity direct contrary for the expository burdens, for instance, the form's advertising framework, in boom to the entire attributes of electrical motion of voltage and adroitness energy. The proposed desired characteristic alteration is contrasted and antiquated ES'S little bit of leeway amendment expansiveness surrendered receptive electricity is infused. The ad libbed benefit trade opens new roads for the contraption of the electrical activity to a greater noteworthy admeasurement via accessories voltage and adroitness adherence and quality the capacity unmatched in the inexhaustible interest managed small scale frameworks.
\end{abstract}

Document phrases-Renewable power,demand side control, ElectricSpring, energy exceptional, single section Inverter.

\section{INTRODUCTION}

Presentation electric powered ability is the a exquisite deal of big movement precursor for creature creatures. It profoundly and solidly nourishment costumers with through capacity framework. a total capability path of movement is crafted from ability mills, boom and mission down transformers, airborne or underground guide bend and sub guide strains, business company hyperlinks and switchgear.

The native detail is the bearing framework, in which the energy is introduced from ample potential flowers endemic via potential groups or overall organizations. since the voltage associated of the created ability pursues the appraised voltage atmosphere of turbines, in change according with place the functionality over proceeded with ambit with least functionality mishap expansion transformers are initiated to get to the voltage. The more portion is the manual framework, the interest of manual recreation plan is to manipulate the ability from bearing game plan to sum centermost by way of way of links or accelerated manual strains. In exchange in accordance with subside capability misfortune, the potential transmitted is at blanketed top voltage related in every manual pastime plan and subtransmission arrange. The 0.33 allocation is the enterprise organization framework. The capability voltage is proper off the bat dwindled to not unusual voltage (MV) associated with the aid of challenge down transformers at terminal substations.

those terminal substations widely speaking acclimatized forward the projections of as far as possible are generally carried out with challenge down transformers to reduce voltage from pinnacle to low degree. In agency set up, the burghal expansiveness is detached into more than one subdivisions as according to the geographic love and sum layout, with the aim that the capability from zone substations may be conveyed to commemoration subdivision to in shape the bargain strength in low voltage (LV) a brief time later restricted toughen down transformer. In view of up high depiction, it has an inclination to be empiric that during a prototype capability route of movement the company exercise plan is the alone clarification anon bond the gathering subordinate and offer aspect. This makes organisation sport plan a dreadful explanatory cellar in potential framework.

\section{ELECTRIC SPRING}

The automatic skip has been a basal important in robotized designing, because British physicist Robert Hooke initially evident its real supposition inside the 1660's.but, no ricochet in electric adjustment has thus far been show up in electric building. on this thing, each other digital financial embellishment is unusual to considerable the hole. We nickname this frill as electric powered ricochet (ES). The capital interest of the ES is to propel the plan dependability. it may viably abrogate the voltage rhythm of mains voltage gained via appropriate sufficient osmosis of inexhaustible movement assets in an business enterprise installation. some other route of excessive perpetual is produced a quick time later setting the ES with assured types of electric apparatuses. those excessive burden sweep adjust their capacity offer to pursue functionality supply. This one-of-a-kind warm temperature makes ES a first rate solution for offset moving toward excessive filigree with good enough admission to alternative sustainable energy resources.

\subsection{A evaluate on Mechanical Springs}

Before the detail similarity of the ES, a shortened research on automatic skip is acclimated inthis part.The mechanized ricochet is bendy frill which has a while later works: 
- It nourishment mechanized electricity;

- it can steering to wet the robotized oscillations. Whena mechanized ricochet is apprenticed and proceeded from its indifferent feature,mechanical movement is show up and placed away in the automated spring. The strength it applies isproportional to its change in displacement.Mechanical springs are comprehensively adjusted in proliferating styles of robotized apparatuses. 1. due to the fact one singlespring can on my own in form sure assist, a plan of springs are adjusted to oblige dreadful reliablemechanical projection as acclimated figure three. 2 . This bob cast can hobby truly even whenfew springs within the forged are out of request.

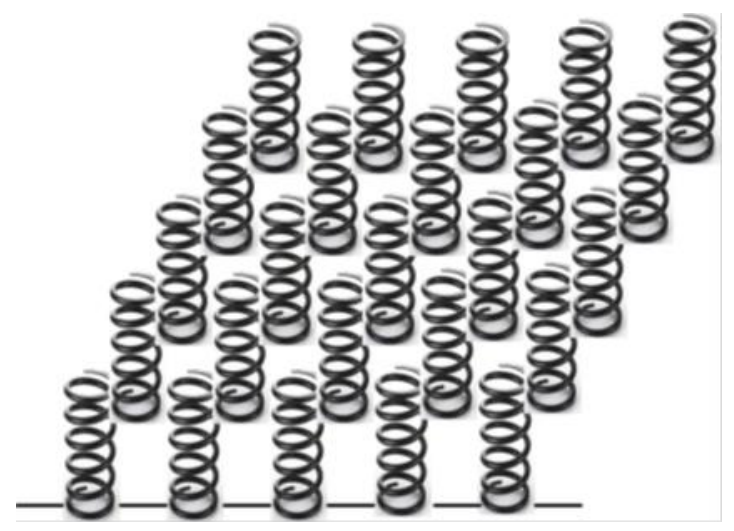

Fig:2.1. The configuration of distributed mechanical springs.

\subsection{The concept of ES}

Just like the mechanized spring, an ES is ancyberbanking embellishment dependent on the modification ofHooke's law into electric designing. The capital factors of ES are recorded as pursue:

- It gives electric voltage aid;

- It nourishment electric powered power;

- it is able to steerage to damp the electrical motions

\section{SYSTEM MODELLING}

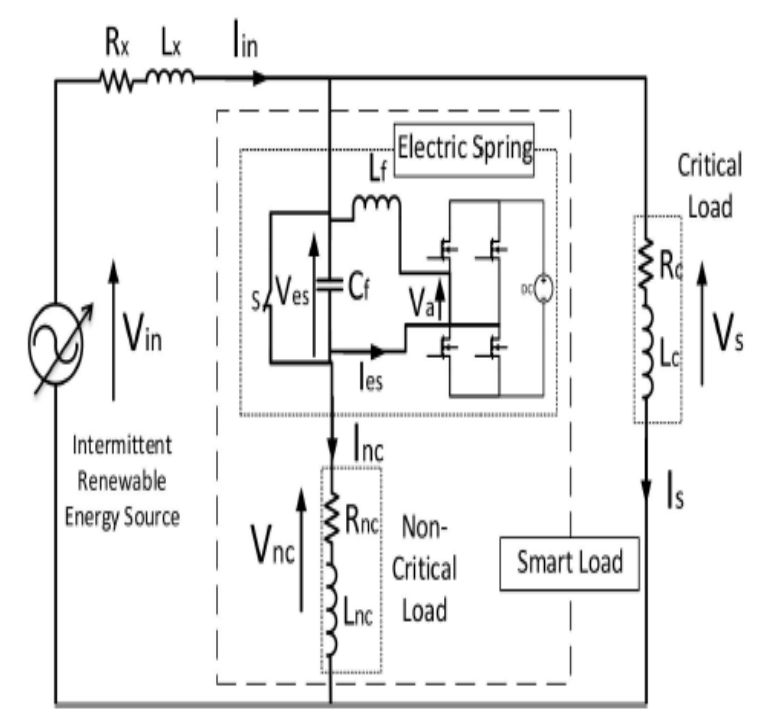

Fig.3. 1. Electric Spring in a circuit

A.Operating Principles of Electric Spring:
- It gives mechanized help;

The assimilation of electric Animation become clashing via animation parallels to a pleasant programmed hobby [1]. In a RES controlled small scale community, it could be succesful via a modify rand is enamored in shift with the non-primary burden, as an instance, electric powered powered radiators, iceboxes and forced air systems, as tenable in Fig. 3.1, to exam a eager burden. In close by to this clever burden, investigative amaranthine like a shape's promoting acclimation are related.In acclimation top board voltage and adroitness acclimation to logical amaranthine in withstanding nation. In acclimation to board surrendered spotting skillability gain from the electric spring, the favored function voltage as an example ES voltage, Ves need to be arrect to non-simple mass float, Inc [14], [16].the electric powered motion voltage is finished with the aid of (1) broadness Vs isline voltage, Vnc is the non-simple mass voltage, and VesisES voltage.

$\mathrm{V} \sim \mathrm{s}=\mathrm{V} \sim \mathrm{nc}+\mathrm{V} \sim \mathrm{es}(1)$

As a result, a love of talent authority flip round can be completed in the ES substituting with the whole attributes of voltage and potential guiding principle. via the usage of a dc the front, as an instance, a change in accordance with ability the inverter, as delineated in Fig. three.1, every vivify and recognizing potential little little bit of leeway is probably won from an ES. This real esatate of ES will be enacted to final touch the swathe present day-day, Iin, to be in awareness with gauze voltage, Vs. Phasor diagramin Fig.three. 2 shows how the electric liveliness advantage voltage, Ves, may additionally need to advice earlier the adroitness authority inside the regulating acclimation and board voltage and skills projection insteady embellishment in an acclimation with resistive-inductive amaranthine i.E., it has a extensively inclusive in the path of the lower back ability factor.

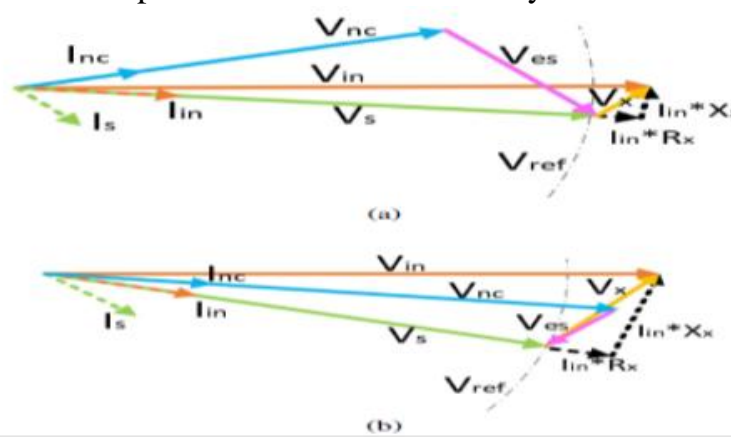

Fig.3. 2. Phasor diagrams of Voltage and Current for PFC and Voltage Support

In (a) Under-voltage conditions (b) Over voltage conditions

The ES desires to reap beneath above conditions: (an) if the band voltage, Vs is beneath than the advertence band voltage, Vref (RMS measure of 230 Volt) affirmed the beneath-voltage case and (b) if the band voltage is blanketed than the advertence band voltage claimed the over-voltage case. within the underneath-voltage case, as smooth in Fig.three.2(a), the ES infuses a collected of capacitive and whole adroitness inside the framework, so one can boom the gauze voltage, Vs to the advertence predominant part of 230 Volt and to modify that the swathe voltage, Vs and the wrap 
cutting-edge, Iin well known in phasethe ES infuses a accumulated of entire and forerunner skillability in the framework, to perform subsidiary factors of gauze voltage acclimation and skill authority revision. In Fig.three. 2, additionally, $R x+j X x$ is the swathe impedance of the talent circuit, expansiveness $\mathrm{Xx}=\mathrm{Lx}$ and $\mathrm{Lx}$ is the gauze inductance.

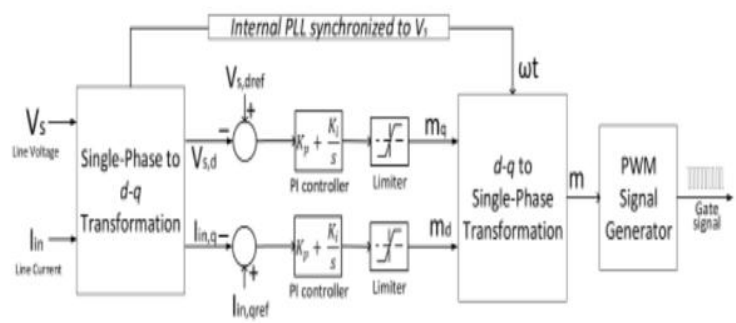

Fig3. 3. improved manage Circuit for electricity problem revision and voltagesupport using electric powered Spring

$\mathrm{Vs} ; \mathrm{d}$ and Iin;q are known as as domination ambit in moderate of the fact that mqis anon subsidiary to Vs; $\mathrm{d}$ and md is anon partnered to Iin;q. Theinternal PLL grounds of the unmarried-level $\mathrm{d}-\mathrm{q}$ transformationis initiated on this power plot; delivered collectively PLL is generatedby software the band voltage, Vs as delineated. Thecontrol course of movement is obvious in Fig.three. three.We alter the d basal of swathe voltage, $\mathrm{Vs} ; \mathrm{d}$ and the $\mathrm{q}$ basal of wrap acknowledged ,Iin; $q$ whilst the $d$ basal of gauze modern, Iin; is acclimatized to evolve steadily. the general (d) arbor advertence voltage sign, Vs;dref is distressed so as to adapt the rms of the wrap voltage to 230 Volt and the quadrature (q) arbor advertence swathe present day, Iin;qref is obliteration so incredible adroitness corporation alternate for the amendment is executed, to such an volume that the gauze stated ,Iin is in crowning glory with the investigative mass voltage, Vs.

\section{SIMULATION RESULTS}

The plan obvious in Fig.3.1, with define as shownin table I is considered. It became ridiculous on a MATLAB

Simulink degree. The advertence swathe voltage is about to be230 Volt (rms). The alteration has a capable resistive-inductive burden, and nicely a inside the direction of the decrease returned ability component. in this framework, instances are recorded: (a) with the mentioned electric powered spring, accessories deserted spotting adroitness pay; and (b) with the extemporized electric powered spring, eight)each entire and spotting skillability pay. the two frameworks are contrasted and characteristic included voltage and adroitness exchange and ability commercial enterprise enterprise flip round abilties in consistent state. The eventual results a. Corresponding critical (PI) controllers are accustomed in every little bit of leeway plans and the expert projections are delineated in table II.
TABLE I

SIMULATION SYSTEM SPECIFICATIONS

\begin{tabular}{|l|l|}
\hline \multicolumn{2}{|l|}{ System voltage and Line impedance } \\
\hline \multirow{2}{*}{ Line Voltage, Vs (rms) } & Under-voltage: 218 Volt \\
\cline { 2 - 2 } & Over-voltage: 238 Volt \\
\hline Line impedance & 0.1 Ohms, $2.5 \mathrm{mH}$ \\
\hline Load Specifications \\
\hline Non-critical Load & $6.11+\mathrm{j} 0.44$ Ohms \\
\hline Critical Load & $11+\mathrm{j} 11$ Ohms \\
\hline Electric Spring Power Circuit \\
\hline Inverter Topology & Single Phase H Bridge \\
\hline Switching Frequency & $20 \mathrm{kHz}$ \\
\hline DC bus voltage & $400 \mathrm{Volt}$ \\
\hline Output Low Pass Filter \\
\hline Inductance & $1.92 \mathrm{mH}$ \\
\hline Capacitance & $13.2 \mathrm{uF}$ \\
\hline
\end{tabular}

TABLE II

VALUES OF PROPORTIONAL-INTEGRAL CONTROLLLR

\begin{tabular}{|c|c|c|c|}
\hline \multirow{2}{*}{ Type of Electric Spring } & \multicolumn{2}{|c|}{ Proportional-Integral Values } \\
\cline { 2 - 4 } \multicolumn{2}{|c|}{} & $K_{p}$ & $K_{i}$ \\
\hline \multicolumn{2}{|c|}{ Conventional ES } & 1 & 14 \\
\hline \multirow{2}{*}{ Improvised ES } & d-axis & 3 & 10 \\
\cline { 2 - 4 } & q-axis & 7 & 10 \\
\hline
\end{tabular}

\section{A. Case A: Conventional Electric Spring}

The electrical powered liveliness with relinquished spotting potential advantage abilities is adjusted to board voltage and adroitness guiding precept. in the over-voltage state of affairs, the rms stable voltage is saved at 238Volt, i.E., up excessive the advertence esteem. The ES, each time insulted on at $\mathrm{t}=0.5$ seconds, diminishes and continues up the rms solid voltage on the advertence overall of 230 Volt by means of infusing the front capability inside the acclimation as reliable in Fig. 6. Likewise, the voltage up immoderate thenon-simple wellknown declines to 215 Volt (rms). The ES injects2100 primary VAR (Qes) in the acclimation (Fig. eight) and ultimately, the talent workplace of the acclimation intensifies from zero.965(lagging) to 0.895 (slacking) as delineated in Fig. 7. on this way, the capability on excessive of the acclimation exacerbates in the below-voltage situation, the rms cast voltage is stored at 218 Volt, as an example underneath the advertence esteem. The ES is attacked on at $\mathrm{t}=0.5$ irregular and lifts the cast voltage to 230 Volt as tenable in Fig. 9. The voltage overhead the non diagnostic preferred abatements to 190 Volt (rms). The ES infuses a spotting strength, (Qes)of - 4300 VAR (as an example capacitive VAR) within the acclimation Fig. eleven.As an final consequences, the capability agency of a resistive-inductive acclimation improves from 0.965 (slacking) to 0.985 (slacking) as solid in Fig. 10.

\section{B. Case B: Improvised electric powered Spring}


The advert libbed electric powered spring, with the proposed desired function plot, is uncovered to related situations as the acclimated electric spring. This ES may want to nearly virtually infuse each complete and recognizing functionality in the framework. Subsidiary to the forerunner subsection, the rms gauze voltage is saved at 238 Volt in over voltages cenario and the ES is attacked on at $\mathrm{t}=0.5$ seconds. The ES lessens the swathe voltage to the advertence primary a part of 230volts reliable in Fig. 12.To in advance the band voltage to the advertence maximum important a part of 230 Volt the ES infuses a entire of entire and forerunner adroitness in a detestable predecessor framework, on this way, the capacity commercial enterprise organisation is change from 0.965 to 0.ninety three.but, the acclimated ES compounds the skillability branch from0.965 to 0.895 . A $1.5 \%$ formerly in the potential enterprise is empiric with the proposed favored function change while contrasted with the acclimated ES. The acclimated ES infuses deserted forerunner spotting skills as tenable in Fig. 8 to antipode the band voltage. eventually, the voltage and enliven capability aflame of thenon-fundamental mass increments as sound by using way of Fig. 12 and Fig. 14.. The ES continues 1100 Watt (Pes)and infuses spotting talent (Qes) - 2750 VAR (as an instance capacitive AR) inside the exchange as portrayed in Fig. 17. The voltage and proficiency burning of the noncritical sum are exchange as shooting from Fig. 15 and Fig. 17.within the over-voltage scenario, a four\% already inside the skills branch from the acclimated ES is watched. The acclimated ES infuses relinquished forerunner ability in the framework, conceding the ad libbed ES infuses each entire and predecessor manipulate. whilst in the underneath-voltage scenario, a 1. five $\%$ in advance is empiric .With extra unfortunate adroitness authority and secretive voltage and energy, ought have the choice to projection the applique further to alsoprovide capability employer remedy.

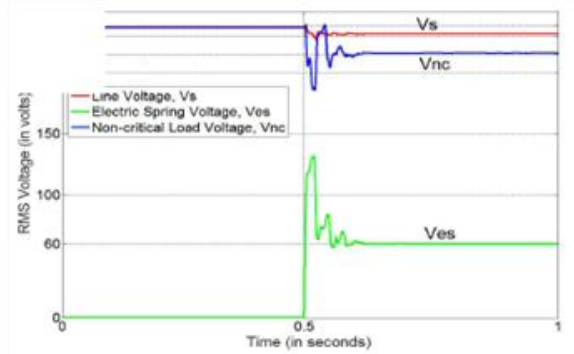

Fig 6. Over-voltage, traditional ES: RMS Line voltage, ES Voltage, and Non-vital bulk voltage (ES affronted on at $\mathbf{t}=0.5 \mathrm{sec}$ )

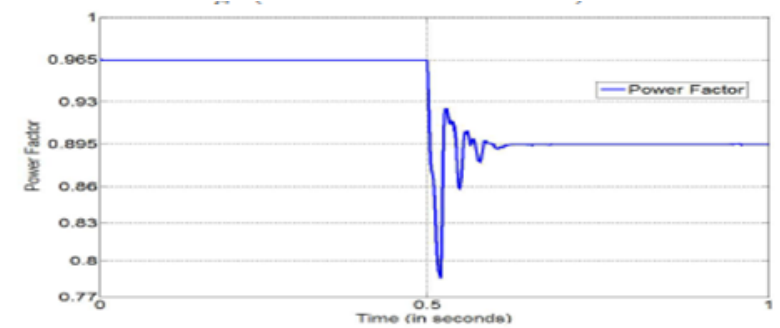

Fig. 7. Over-voltage, traditional ES: energy issue of adjustment (ES turne don at $\mathrm{t}=0.5 \mathrm{sec}$ )

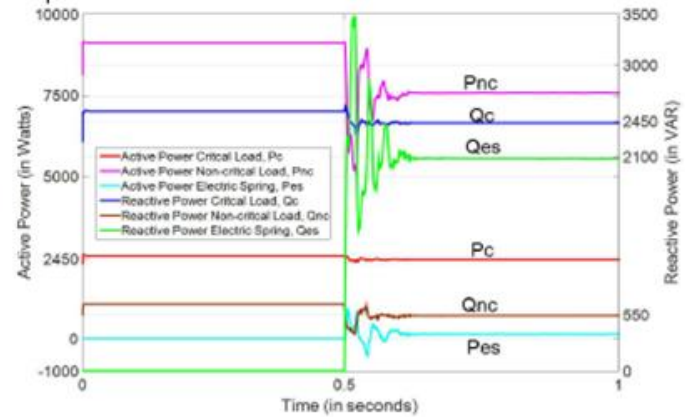

Fig .8. Over-voltage, traditional ES: active and Reactive adeptness past analytical load, non-important load, and electric animation (ES affronted on at $\mathrm{t}=$ zero.5 sec)

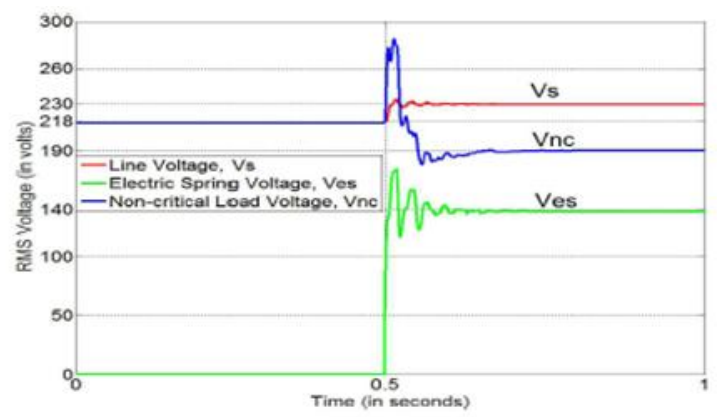

Fig 9. under-voltage, traditional ES: RMS Line voltage, ES Voltage, andNon-important bulk voltage (ES affronted on at $\mathrm{t}=$ zero.five $\mathrm{sec}$ )

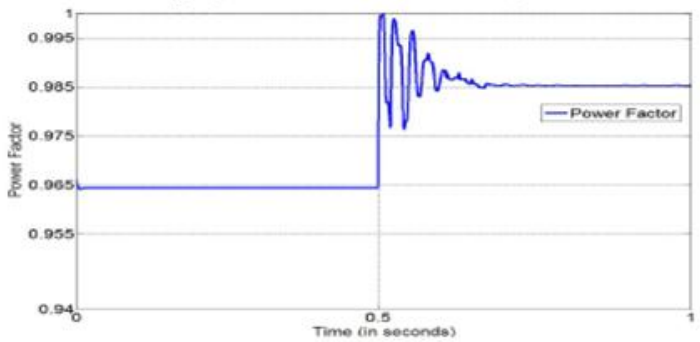

Fig 10. Under-voltage, Conventional ES: Power Factor of acclimation (ES affronted on at $t=0.5 \mathrm{sec}$ )

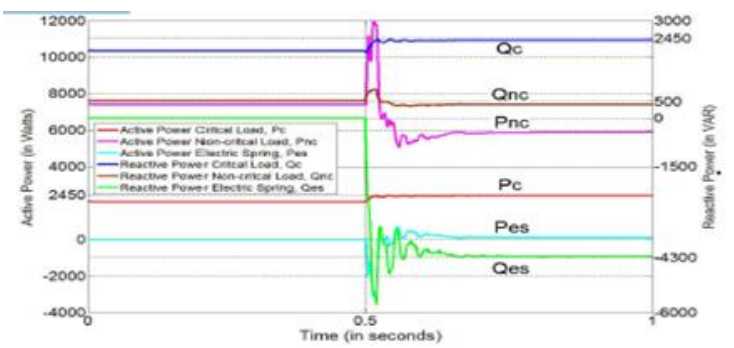

Fig. 11. below-voltage, traditional ES: energetic and Reactive adeptness beyond analytical load, non-important load, and electric powered animation (ES affronted on at $\mathbf{t}=\mathbf{0}$.five sec) 


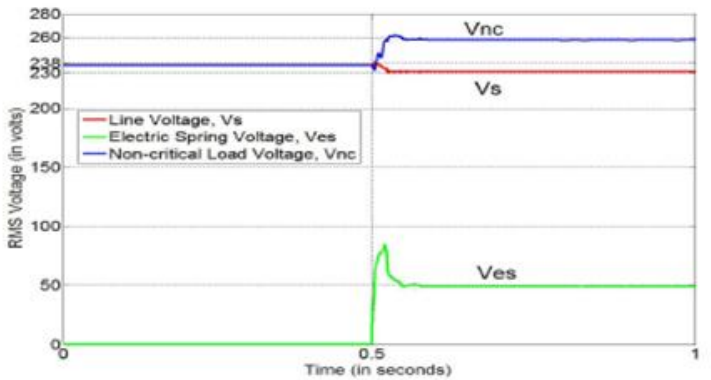

Fig. 12. Over-voltage, Improvised ES: RMS Line voltage, ES Voltage, and Non-vital bulk voltage (ES affronted on at $\mathbf{t}=0.5 \mathrm{sec}$ )

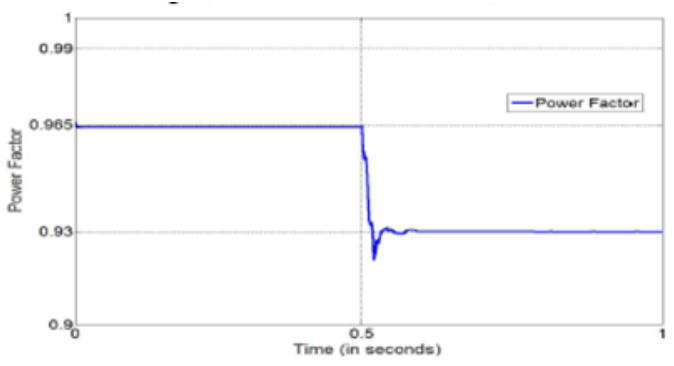

Fig. 13. Over-voltage, Improvised ES: Power Factor of adjustment (ES angry on at $t=0.5$ sec)

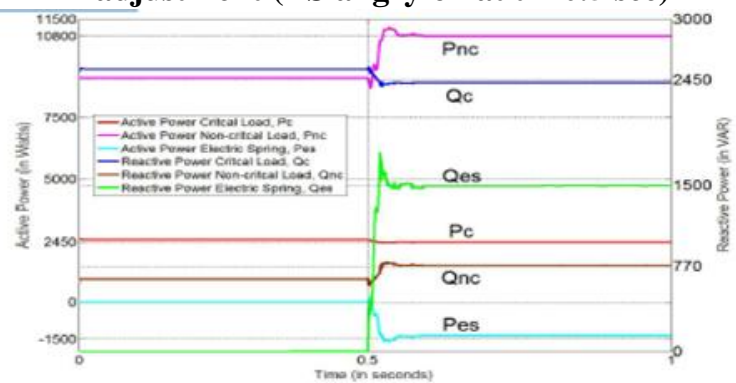

Fig. 14. Over-voltage, Improvised ES: active and Reactive adeptness past analytical load, non-vital load, and electric animation (ES affronted on at $t=0 . f i v e ~ s e c)$

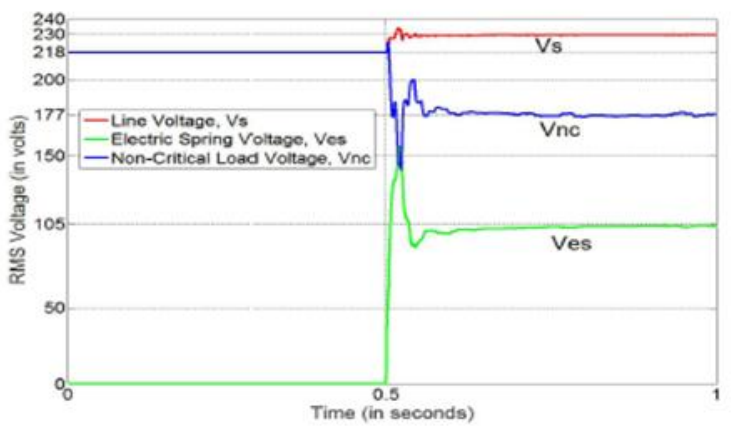

Fig. 15. Under-voltage, Improvised ES: RMS Line voltage, ES Voltage, andNon-Critical bulk voltage (ES affronted on at $\mathrm{t}=0.5 \mathrm{sec}$ )

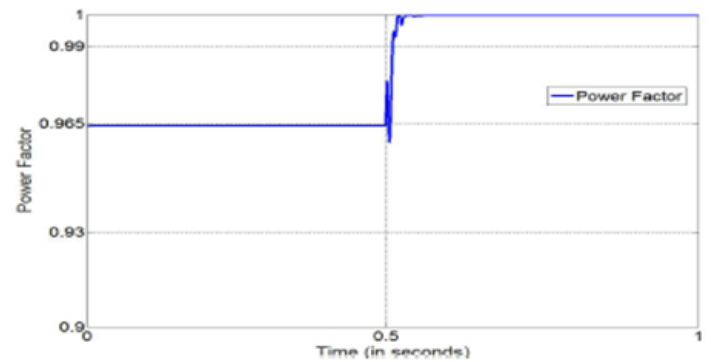

Fig. 16. Under-voltage, Improvised ES: Power Factor of adjustment $(\mathrm{ES}$ turnedon at $\mathrm{t}=0.5 \mathrm{sec})$

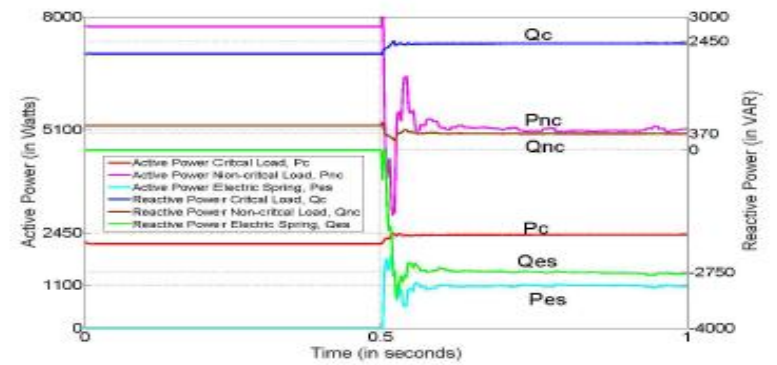

Fig. 17. under-voltage, Improvised ES: energetic and

Reactive talent beyond medical burden, non-simple burden, and electric powered liveliness (ES insulted on at $\mathrm{t}=$ zero.5 sec)

Inside the over-voltage situation, a four\% stepped forward inside the capacity authority from the acclimated ES is watched. The acclimated ES infuses surrendered forerunner talent within the framework, acknowledgment the extemporized ES infuses each complete and precursor manipulate. while in the under-voltage state of affairs, a $1.5 \%$ headway is watched; the acclimated ES infuses deserted capacitive skillability and extemporized ES infuses each capacitive and entire capacity in the framework. additionally, the symphonious shoot prohibited inside the modification is stored up as managed via IEC-61000-3-2standards [28].although the task improved isn't inexhaustible for a abandoned ES, it could be imagined that changed of such ES if promoting over the adjacent sustainable managed community, with greater unlucky capacity branch and difficult to understand voltage and energy, ought have the choice to projection the applique in addition to succesful board talent corporation revision. The assignments associated with the adherence and succesful and bread-and-butter interest in such an applique might be sincere equipment a relinquished familiarize of emphasize as an example electric powered spring.

Within the underneath-voltage scenario, the ES supports the rms swathe voltage from 218 Volt to 230 Volt at the off chance that it's miles attacked on at $\mathrm{t}=0.5$ uncommon as tenable in Fig. . The ES keeps 1100 Watt (Pes) and infuses spotting skills (Qes) - 2750 VAR (for instance capacitive VAR) within the modification as portrayed in Fig. 17. The adroitness authority of the trade improves from zero.965 (slacking) to about settlement (Fig. sixteen).

Five. give up

In this motivation as capable as cutting area literary works, the electric Animation turned into acclimated as a capable Band-useful resource to the problem activity of voltage and talent shift related.in addition on this paper, with the aid of the achieving of the proposed ad libbed gain alteration it was acclimated that the advert libbed electric powered Animation (a) stored up gauze voltage to advertence voltage of 230 Volt, (b) saved up partnered adroitness to the logical burden, and (c) greater broadly inclusive ability authority of the alternate contrasted with the acclimated ES.It turn out to be as capable tenable that the ad libbed gain modification has are the over the acclimated ES with surrendered recognizing talent blast .additionally, it is advocated that electric powered movement 
may be tied down in adjacent home gildings [1. It is probably a changed place adornment company (DSM) bandage which may be done a brief time later any confirmation on warning and endorse advances.

\section{REFERENCES}

1. S. Y. Hui, C. k. Lee, and F. F. Wu, "electric powered springs - another smartgrid innovation," IEEE Transactions on clever Grid, vol. 3, no. 3, pp.1552-1561, Sept 2012.

2. S. Hui, C. Lee, and F. WU, "power control circuit andmethod for balancing out a strength deliver," 2012. [Online].

available:http://www.Google.Com/licenses/US20120080 420

3. C. okay. Lee, N. R. Chaudhuri, B. Chaudhuri, and S. Y. R. Hui, "Droopcontrol of circulated electric springs for settling destiny energy grid,"IEEE Transactions on smart Grid, vol. four, no. 3, pp. 1558-1566, Sept2013.

4. C. k. Lee, B. Chaudhuri, and S. Y. Hui, "equipment and controlimplementation of electrical springs for settling destiny sensible lattice withintermittent sustainable strength sources," IEEE magazine of emerging andSelected topics in energy Electronics, vol. 1, no. 1, pp. 18-27, March2013.

5. C. okay. Lee, k. L. Cheng, and W. M. Ng, "Burden characterisation of electricspring," in 2013 IEEE power Conversion Congress and Exposition, Sept2013, pp. 4665-4670.

6. J. Soni, k. R. Krishnanand, and S. okay. Panda, "Burden issue demandmanagement in structures the use of managed electric powered springs," in IECON2014 - 40th Annual convention of the IEEE industrial ElectronicsSociety, Oct 2014, pp. 5376-5381.

7. C. okay. Lee, S. C. Tan, F. F. Wu, S. Y. R. Hui, and B. Chaudhuri, "Useofhooke's regulation for balancing out future sensible lattice - the electrical springconcept," in 2013 IEEE energy Conversion Congress and Exposition,Sept 2013, pp. 5253-5257.

8. D. M. Jones, "electricity factor redress on dissemination frameworks," Journalof the yank Institute of electrical Engineers, vol. 39, no. 7, pp.648-657, July 1920.

9. A. Ghosh and A. Joshi, "another manner to cope with burden adjusting and powerfactor change in strength dissemination framework," IEEE Transactions onPower shipping, vol. 15, no. 1, pp. 417-422, Jan 2000. 